\title{
Performance of Under-Reamed Piles in Collapsible Soil
}

\author{
Hayder A. Mahdi ${ }^{1, a^{*}}$, Omar k. Mohialdeen ${ }^{2, b}$, and Amer G. Jihad ${ }^{3, c}$ \\ ${ }^{1}$ Civil Engineering Department, University of Baghdad, Baghdad, Iraq \\ ${ }^{2}$ College of environmental science and technology, University of Mosul, Mosul, Iraq \\ ${ }^{3}$ Department of Road and Transport Engineering, Al-Qadisiyah University, Iraq \\ aAlwan@coeng.uobaghdad.edu.iq, bomar.k.aldeen@uomosul.edu.iq, \\ camer.ghani@qu.edu.iq
}

\begin{abstract}
One of the Iraqi geotechnical problems is the presence of gypseous soils covering about (27-36) percentage of Iraq soils containing gypsum between (10-70) ratios. The main reason for soil problematic is the gypsum dissolution when these soils are inundated. However, the soluble gypsum can be leached out of the soil particles, so these problems can be led to cracking, tilting, and collapsing the related soil structure and changing the soil properties. The aim of this work is to investigate the performance of under-reamed piles as a new, improved method to reduce the moisture sensitive and the primary triggering mechanism for the volume reduction of collapsible soil, which is considered as a non-elastic deformation; this was done by carrying series of inundation these soil with using different types of under reamed piles to arrive the best and suitable type useful in gypseous soils. The piles with reams are concrete piles with one or more ream, so under-reamed piles are suitable in weak soils where sizable ground movement, variations, filed up ground, silty clay, and loose sand which has the advantage to increase the soil strength. This paper includes the experimental model of underreamed piles under static load simulated by a steel plate on the pile cap, then the load-settlement curve, friction force, and bearing force founded from the investigation of different patterns of reamed. It was found that a number of bulbs had a significant reduction on settlement reach to $93 \%$ in case of using triple under-reamed pile which is the greatest results in comparison with other patterns and reference pile of the uniform cross-section in the wet state.
\end{abstract}

Keywords: Under-reamed pile, static load, gypseous soil.

\section{Introduction}

Many of the engineering problems are confronted due to the degradation of gypsum when such soils by water wetting, soaking, or leaching, especially in sandy gypseous soils, so these issues are normally prompted to break, inclining and collapsing the connected structure $[1,2]$. Problems due to soil collapse, such as the Samarra vacationer hotel, Kerbala raised water tank, and the damage and collapse in the soil under different establishments announced in Tikrit and Mosul City. Al-Busoda and Al-Rubaye [3] scanned the selected soil characteristics from Salah-Aldeen Governorate 70\% gypsum content in dry and soaked conditions. The effects noted that the angle of internal friction is diminished marginally to $12.2 \%$ and $9.2 \%$ after soaking for 6 and 24 hours individually. Moreover, the effects shown that the cohesion properties have a considerable lessening $91.5 \%$ and $94.2 \%$ after saturated for 6 and 24 hours respectively compared to dry conditions [4]. Therefore, it is intended to opponent the reduction in the collapsible soil properties under soaking conditions. Al-Zabedy and AlKifae [5] observed that geogrid improved the bearing capacity of gypsum-soaked soils from 275 $\mathrm{kN} / \mathrm{m}^{2}$ before using reinforcement materials $415 \mathrm{kN} / \mathrm{m}^{2}$.

Noman et al. [6] investigated pile group efficiency according to pile diameter 2D, 4D, and 6D in two types of gypseous soil S1 and S2 with gypsum content $30 \%$ and $61 \%$, respectively under axial. It was found that the pile group efficiency for $2 \mathrm{D}$ is less than one, but for $4 \mathrm{D}$ and $6 \mathrm{D}$ are more than one for both soaked soil S1 and S2, and the result showed that the ultimate load increase in S2 is $(22.4 \%$, $22.1 \%$, and $22 \%$ ) more than that for $\mathrm{S} 1$ at wet state for spacing $2 \mathrm{D}, 4 \mathrm{D}$ and $6 \mathrm{D}$ respectively. Jebur et al. [7] investigated the geometrical shape of reams on the ultimate bearing capacity under dynamic 
load numerically. The result shows that the ream's cone shape is considered the better shape in reduction of vertical displacement (1670\%) than other shapes of under reamed bulbs.

\section{Applications of Under-Reamed Piles}

Under-reamed piles are bored cast in situ concrete piles with one or more enlargements (ream, bulb) near base and pile stems. These reams were increasing both friction and bearing surface and capacity of the pile in compressive loading [8]. So, these types of piles are effectively used in tower foundation, electrical transmission, bridges, and machine foundations. In the same way, the enlargements of pile increased the tensile bearing capacity of these piles, making them appropriate for use in the foundation of structures such as centrifuges, piers, various transmission lines, and others [9]. Christopher and Gopinath [10] Study the behavior of under-reamed piles subjected to vertical loads by experimental work in sand soil compared with straight shaft pile, the pile and under-reamed diameter equal to 25 and $75(\mathrm{~mm})$ respectively. The results show that the under-reamed pile's bearing capacity is higher compared to the straight shaft, about $305 \%$.

\section{Materials Used}

The properties are classified into three groups:

Soil. The soil samples have been collected from a location nearby Al-Rufae road in Karbala city Figure 1 with gypsum content (G.C 30.6\%) but passing through sieve No. 10 and retaining on sieve No. 100. Tables 1 and 2 show the engineering properties and chemical components of soil used.

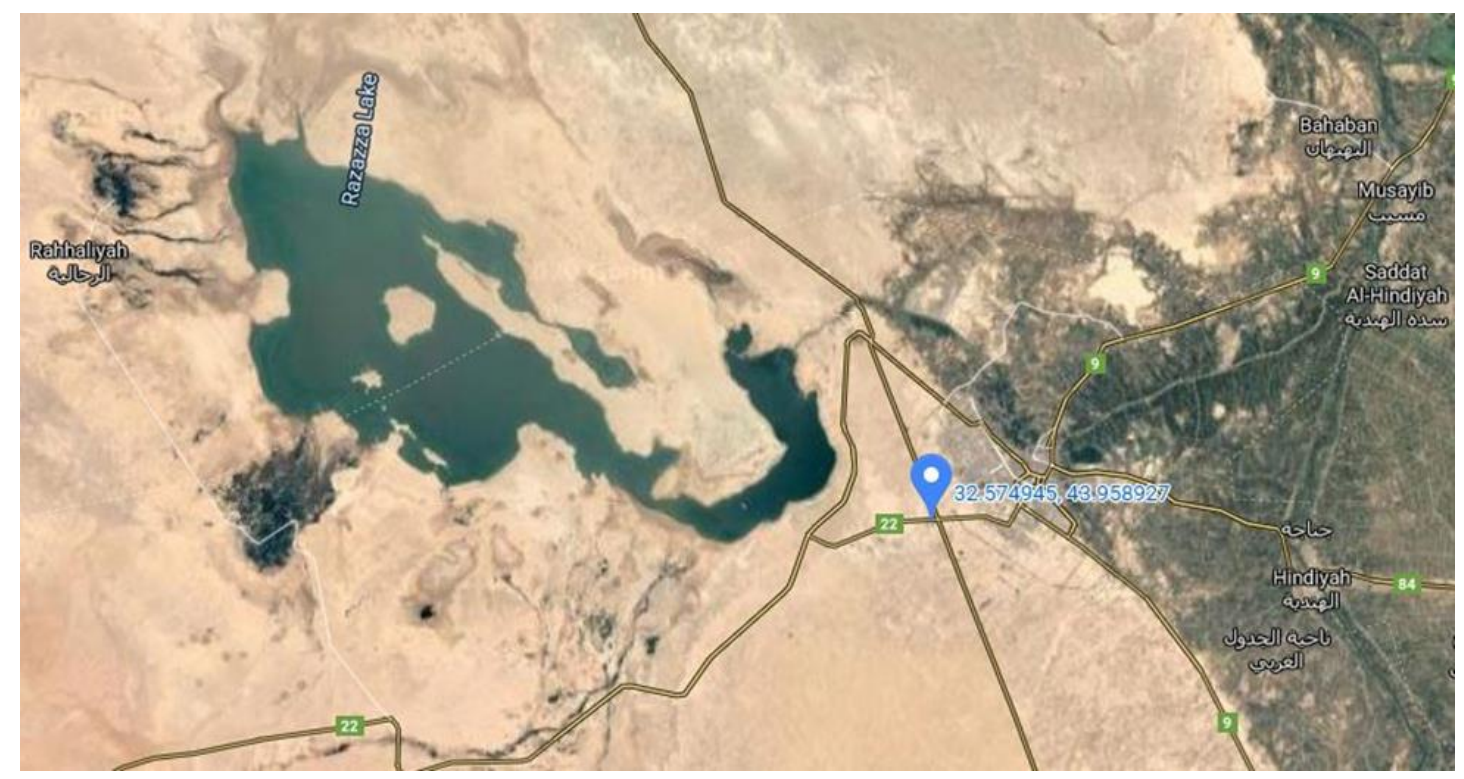

Figure 1. Site from Google Earth.

These soils are used to study the effect of under-reamed pile types on the load-settlement curve. Fig. 2 showed that the gypseous soil (G.C30.6\%) and the collapse potential $6.8 \%$ classified as Moderate severe (ASTM D5533-2003).

Table 1. Chemical components of soil used.

\begin{tabular}{|l|c|}
\hline \multicolumn{1}{|c|}{ Composition } & Magnitude \\
\hline Total soluble salts (TSS), \% & 34 \\
\hline Sulphate content $\left(\mathrm{SO}_{3}\right), \%$ & 12.8 \\
\hline Gypsum content, $\%$ & 30.6 \\
\hline Chloride content $(\mathrm{Cl}), \%$ & 0.06 \\
\hline Organic matters $(\mathrm{OM}), \%$ & 0.15 \\
\hline pH value & 8 \\
\hline
\end{tabular}


Table 2. Some properties of soil used in test.

\begin{tabular}{|l|c|c|}
\hline Property & Value & Specification \\
\hline Specific gravity & 2.54 & ASTM (D854) \\
\hline Coefficient of uniformity & 2.0 & \multirow{2}{*}{ ASTM (D422) } \\
\hline Coefficient of curvature & 0.96 & \\
\hline Classification (USCS) & SP & ASTM (D4253) \\
\cline { 1 - 2 } Maximum unit weight & 17.0 & ASTM (D4254) \\
\hline Minimum unit weight & 14.20 & - \\
\hline Dry unit weight (Used), $\mathrm{kN} / \mathrm{m}^{3}$ & 15.21 & \\
\hline Angle of internal friction & 30 & \\
\hline
\end{tabular}

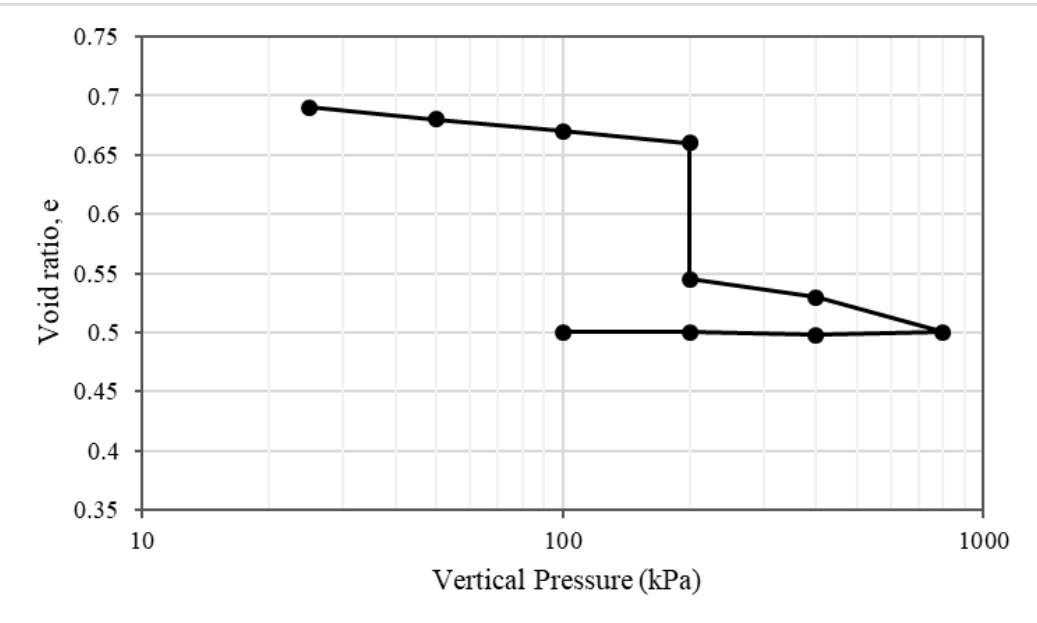

Figure 2. Results of single oedometer collapse test for soil used.

Reinforced Concrete of Under-Reamed Piles. In this study, the piled models are made from reinforced concrete with a diameter of piles (D) $25 \mathrm{~mm}$ and a total length of $620 \mathrm{~mm}$. The pile embedded length (L) $600 \mathrm{~mm}$ and embedment ratio $\mathrm{L} / \mathrm{D}=24$.

Piled Cap Models. In this work, the piled cap models $(100 \times 100 \times 10) \mathrm{mm}$ are made from an iron plate.

\section{Ancillary Equipment}

Numbers of ancillary equipment are attached with the apparatus, as described below:

Force Sensor. This sensor is used to measure the forces directly beneath under reamed pile (pile tip and bulb) with $0.111 \mathrm{kN}$ capacity. The size and thickness of these tactile force sensors are $14 \mathrm{~mm}$ width, $0.203 \mathrm{~mm}$ thickness, and a sensing area of $9.53 \mathrm{~mm}$ diameter along which are suitable for small foundation area and the sensor capabilities were found eligible to be used in this research.

Linear Variable Differential Transducer (LVDT). Computerize linear variable differential transducer (LVDT) for static movement is used in measuring the vertical displacements.

Data Acquisition System. An Italian compatible data logger was used following the sensors manufacturing company recommendations to record all data from force and displacement equipment and display the load variation with the settlement with time using LABVIEW 2019 software.

\section{Testing Procedure}

Preparing the bedding soil of sand according to the required relative density $(35 \%)$ using the raining technique, fill the model box with dimension $(1000 \times 1000 \times 1000) \mathrm{mm}$. The bedding soil 
poured in layers of maximum height $10 \mathrm{~cm}$, considering the location of under reamed bulb or pile tip. When the soil bed preparation process is completed to the desire level (bulb or pile tip) force sensor can be Installation at the desired level where the connecting wires of the force sensor and data logger are extended horizontally to the wall of the soil container, then extended vertically out of the soil container to the data logger. Put the precast model pile of uniform cross-sectional area at the specific depth of $40 \mathrm{~cm}$ from the base of the soil container and above the force sensor. A specially designed steel frame controlled the verticality of the model pile. At the specified location of under reamed bulb, a plastic mold of cone shape is inserted along with the precast pile.

The part of the precast model pile is coated with a structural epoxy bonding agent (Sikadur-23) to ensure good bonding between the model pile and under reamed bulb. The under-reamed bulb is casted by injection mortar by a special needle. Connecting the model pile with a steel pile cap using a screw of $17 \mathrm{~mm}$ and the machine then installing an LVDT on the cap of the model pile to measure the vertical displacement of the model under-reamed pile and connected to data logger and data acquisition system. The water entered the model by control system, the outlet valve at the lower part of the model box was closed to ensure the saturation condition was reached. The soaking period was 12 hours then the leaching process was started by opening the drainage valve and the inlet valve of the water tank with a constant water level (soil surface). Finally, the vertical load is applied to the center of the under-reamed pile cap by plate steel and measure the load variation with settlement using LABVIEW 2019 software Fig. 3.

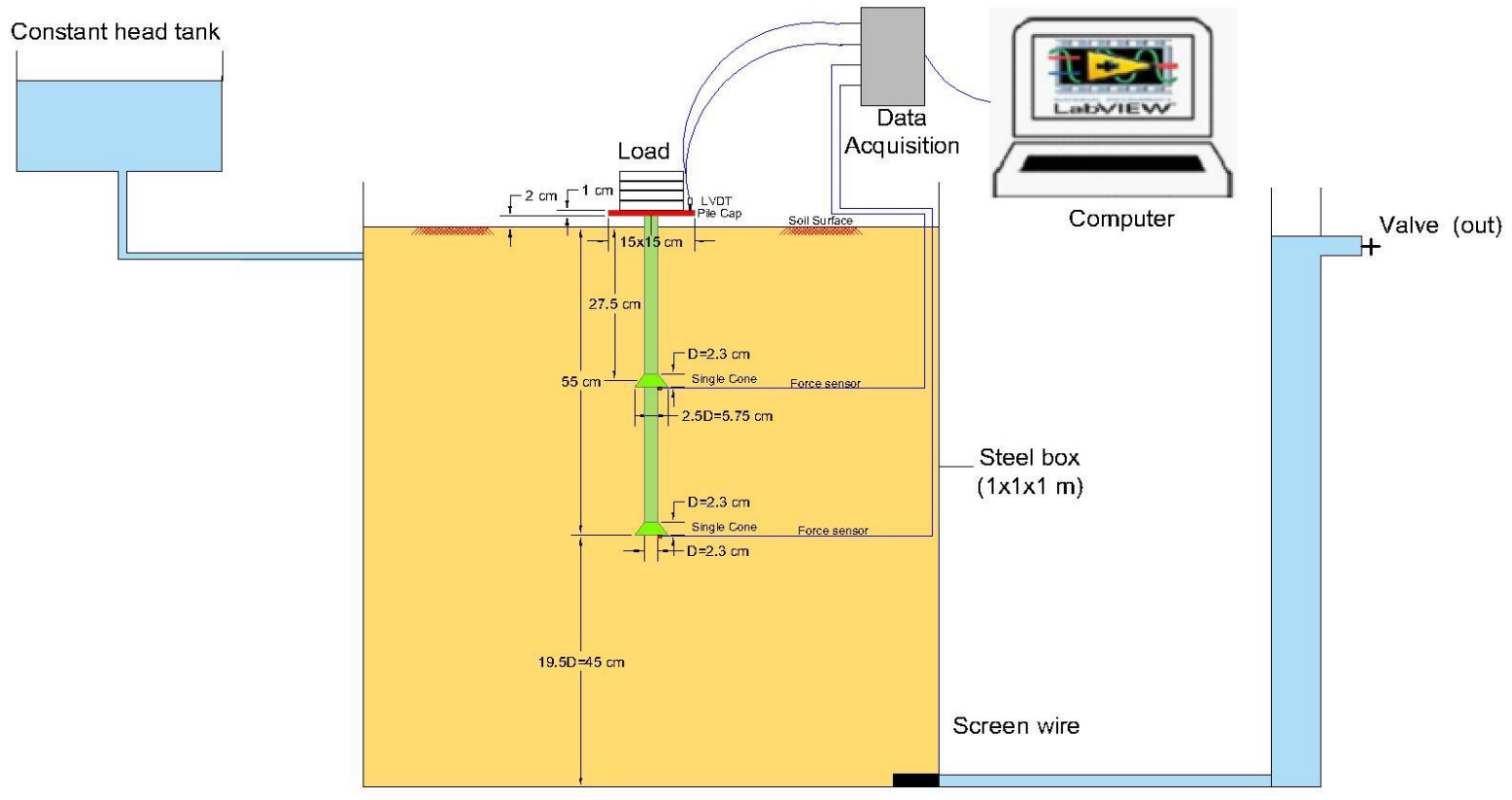

Figure 3. Testing equipment's for the experimental setup.

\section{Results and Discussion}

In this study, the bearing capacity of the under-reamed pile in collapsible soil was experimentally observed by changing the geometry of the under-reamed pile position, spacing, and numbering of the bulb. The reamed position used was $\mathrm{L}=0, \mathrm{~L} / 4, \mathrm{~L} / 2$, and $3 \mathrm{~L} / 4$, as shown in Figure 4 . In the same way, it is intended to study the effect of double bulbs (D.B) spacing of reamed (S1, S2, and S3) Figure 5 and the impact of triple bulbs (T.B) spacing of reamed (N1, N2, and N3) compared with uniform pile Figure 6. To define the ultimate capacity of under-reamed piles, the criterion by Terzaghi (1996) [11] is considered herein. The criterion that considers the failure load is that load that causes displacement equal to $10 \%$ of pile diameter. It can be noted that the addition of one bulb reduces the collapsible soil settlement percent between (26\%-61\%) compared with the uniform pile, and the optimum position of the bulb was in position $\mathrm{L}=0$ and $\mathrm{L} / 4$ due to confining pressure around bulb position increase the bearing and friction force resisting, see Figure 7. 
Figures 8 and 9 showed the load-settlement curve of the under-reamed pile in D.B and TB, respectively; it can be noticed that there is a big reduction in collapsible settlement of under-reamed pile at different spacing compared with the collapsible settlement of the uniform pile under the same load condition. The addition of a double bulb reduced the collapsible settlement percent between ( $80 \%-88 \%$ ), and the optimum DB spacing was S4 Figure 8 . While the addition of triple bulb reduced the collapsible settlement percent between (91\%-94\%) and the suitable spacing was N3 as shown in Figure 9.

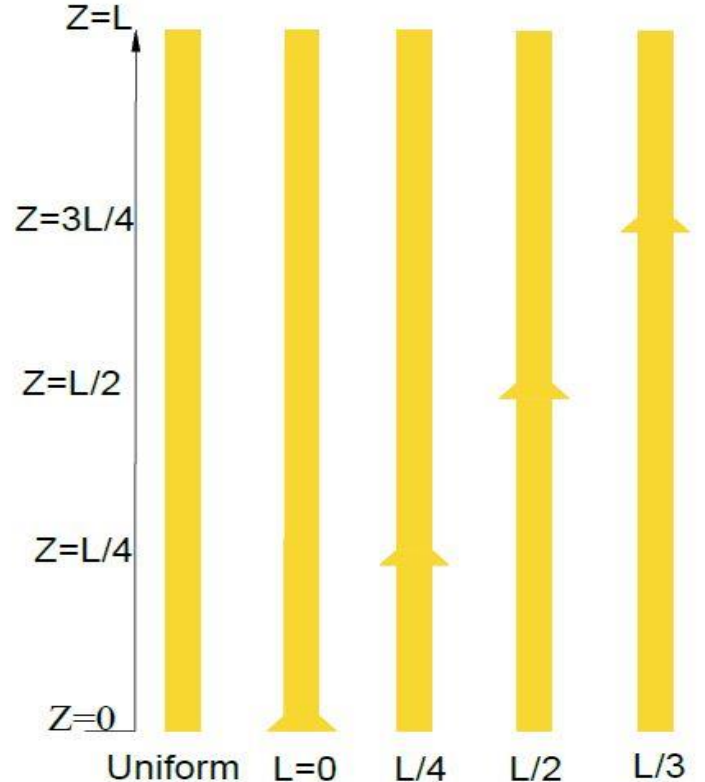

Figure 4. Geometrical position of single under reamed pile.

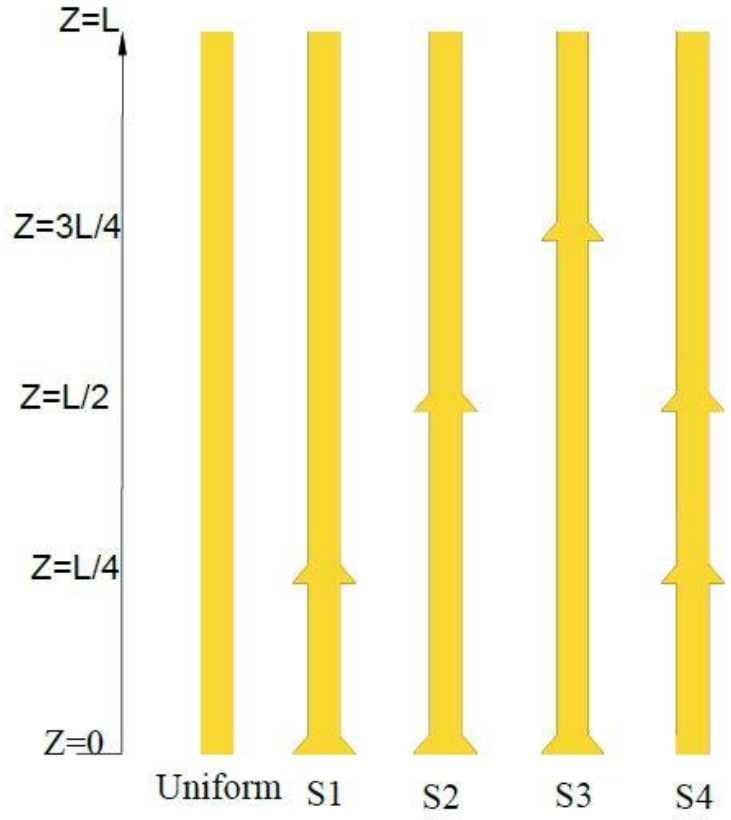

Figure 5. Geometrical spacing of double bulb.

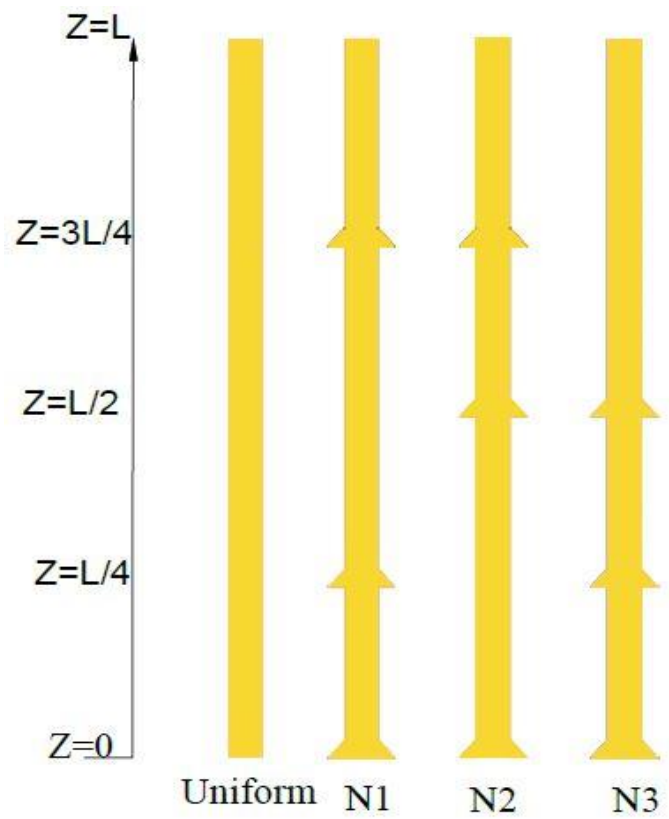

Figure 6. Geometrical spacing of triple bulb. 


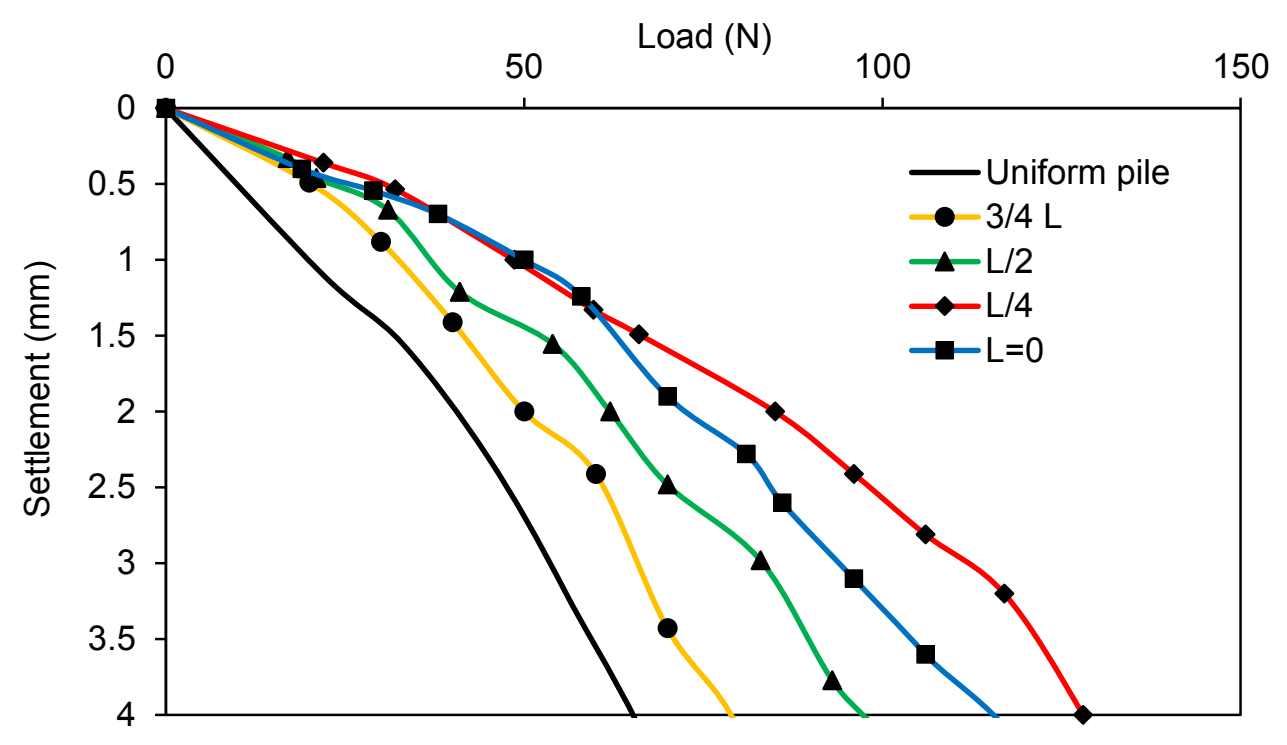

Figure 7. Load-settlement curve with different bulb position.

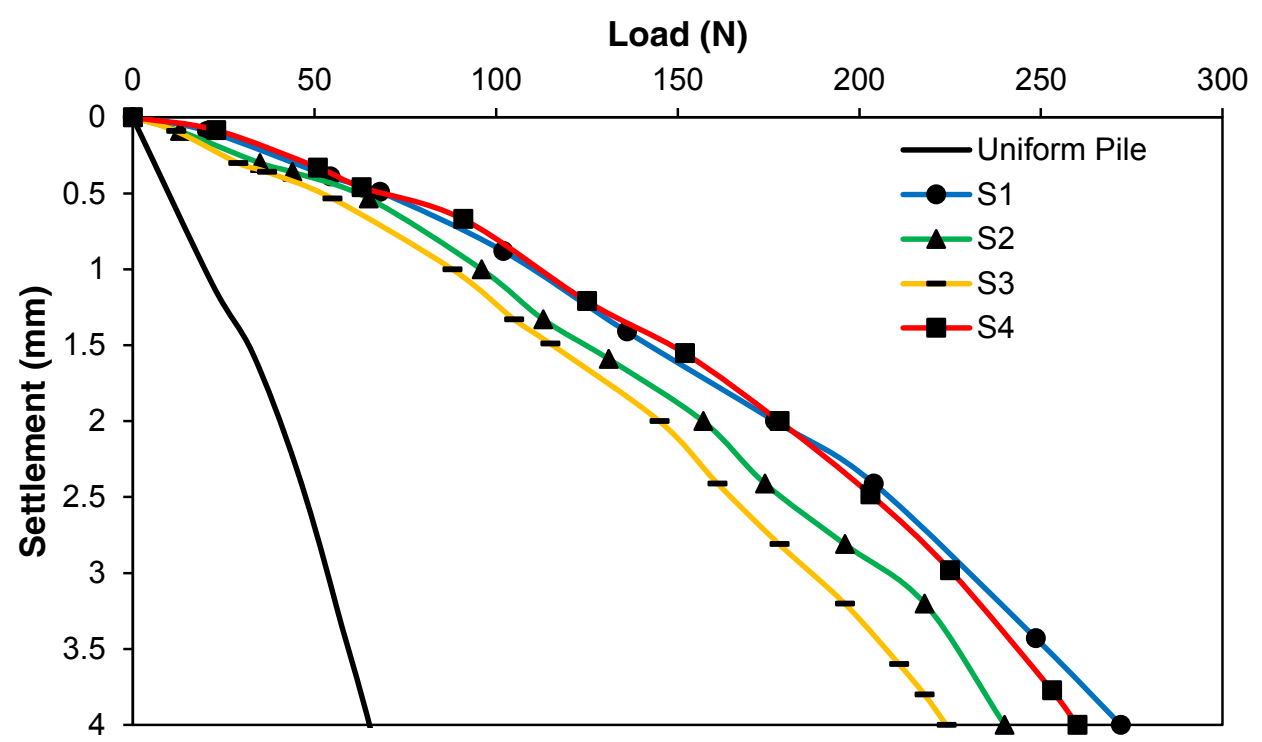

Figure 8. Load-settlement curve with different bulb spacing D.U.P.

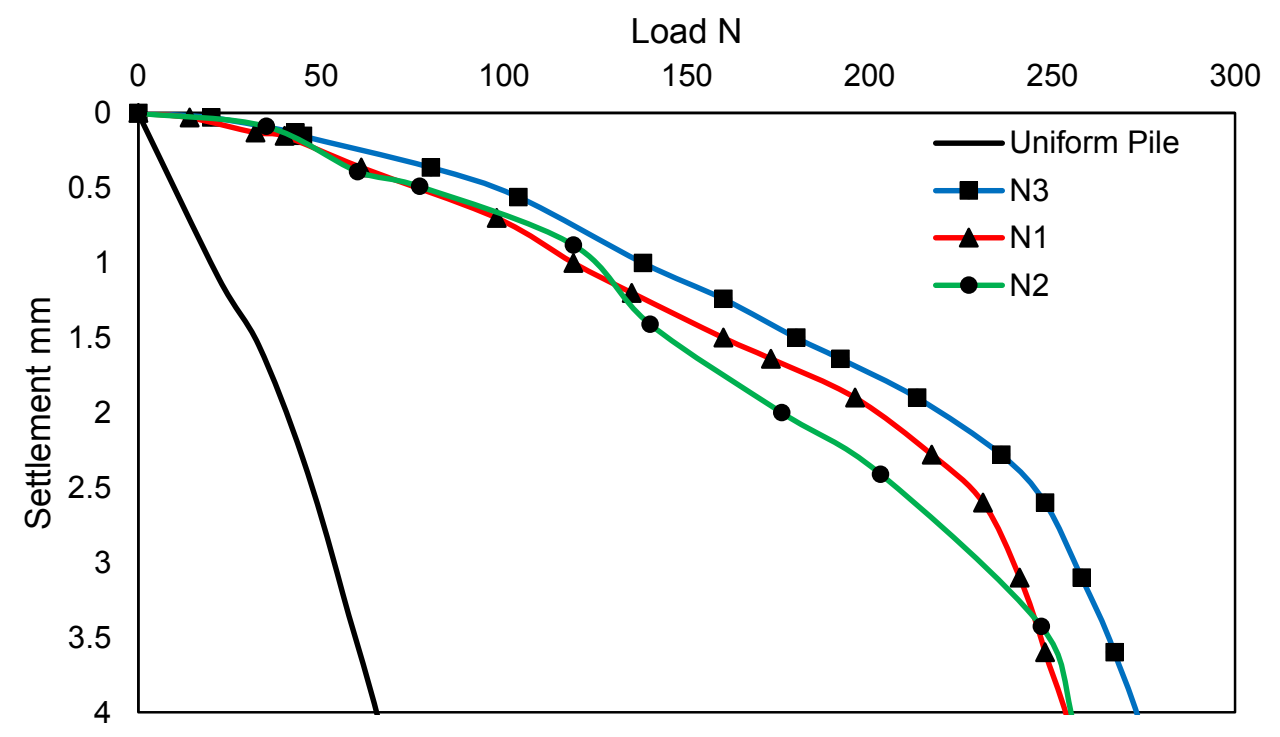

Figure 9. Load-settlement curve with different bulb spacing T.U.P. 


\section{Conclusions}

- This study clearly shows that the factor of safety against bearing failure in collapsible soil increased by under reamed pile under static load.

- It was observed that variation of the position of bulb led to increasing the variation of reduction collapsible soil settlement percent between (26\%-61\%).

- Increase the number of bulbs reducing the settlement of collapsible soil by (26\%-94\%).

- Finally, the relation between the variation of triple bulb spacing and the reduction in settlement of collapsible soil was moderately small about $3 \%$.

\section{References}

[1] Nashat, I.H., 1990. Engineering characteristics of some gypseous soils in Iraq. Unpub. Ph. D. Thesis. University of Baghdad.

[2] Karim, H.H., Schanz, T. and Nasif, M.H., 2012. Improving collapsibility and compressibility of gypseous sandy soil using bentonite and kaolinite. Eng. \& Technology Jour, 30, p.18.

[3] Karim, H.H., Schanz, T. and Nasif, M.H., 2012. Improving collapsibility and compressibility of gypseous sandy soil using bentonite and kaolinite. Eng. \& Technology Jour, 30, p.18.

[4] Schanz, T. and Karim, H.H., 2018. Geotechnical characteristics of some Iraqi gypseous soils. In MATEC Web of Conferences (Vol. 162, p. 01005). EDP Sciences.

[5] Al-Zabedy, S. and Al-Kifae, A., 2020, March. Controlling collapsibility potential by improving Iraqi gypseous soils subsidence: A Review study. In IOP Conference Series: Materials Science and Engineering (Vol. 745, No. 1, p. 012107). IOP Publishing.

[6] Noman, B.J., Abd-Awn, S.H. and Abbas, H.O., 2019. Effect of pile spacing on group efficiency in gypseous soil. civil engineering journal, 5(2), pp.373-389.

[7] Jebur, M.M., Ahmed, M.D. and Karkush, M.O., 2020. Numerical Analysis of Under-Reamed Pile Subjected to Dynamic Loading in Sandy Soil. In IOP Conference Series: Materials Science and Engineering (Vol. 671, No. 1, p. 012084). IOP Publishing.

[8] Jebur, M.M. and Ahmed, M.D., 2020, August. Experimental Investigation of Under Reamed Pile Subjected to Dynamic Loading in Sandy Soil. In IOP Conference Series: Materials Science and Engineering (Vol. 901, No. 1, p. 012003). IOP Publishing.

[9] George, B.E., Compressive load carrying capacity of Multi-Tiny Bulb Pile.

[10] Christopher, T. and Gopinath, M.B., 2016. Parametric study of under-reamed piles in sand. International Journal of Engineering Research \& Technology (IJERT), 5(7), pp.577-581.

[11] Terzaghi, K., Peck, R.B. and Mesri, G., 1996. Soil mechanics. New York: John Wiley \& Sons. 